Małgorzata Piotrowska-Skrzypek Uniwersyteckie Kolegium Kształcenia Nauczycieli Języka Francuskiego Uniwersytet Warszawski m.skrzypek@uw.edu.pl

\title{
ANGIELSKI SZANSĄ DLA FRANCUSKIEGO, CZYLI REFLEKSJA O ZINTEGROWANYM NAUCZANIU JĘZYKOWYM Z PERSPEKTYWY DYDAKTYKI WIELOJĘZYCZNOŚCI
}

\section{English as an opportunity for French: a reflection on an integrated didactic approach to different languages studied from the perspective of pluralistic approaches to languages and cultures}

The supporters of the concept of multilingualism and interculturalism emphasize that learning new languages is more effective when one consciously refers to the past and current experiences in the exploration and use of languages. A person who, in addition to the mother tongue, learned a foreign language and knows how to use it, not only possesses a skill set needed in the process of learning but also has the information about a language system. Referring to the available research on multilingualism, this article outlines the methods of utilizing this potential during foreign language classes and of preparing the ground for a complex program of teaching additional languages.

Keywords: pluralistic approaches to languages and cultures, integrated didactic approach to different languages studied, foreign language, tertiary language learning: French after English

Słowa kluczowe: dydaktyka wielojęzyczności i wielokulturowości, zintegrowane nauczanie językowe, języki obce nowożytne, nauczanie/uczenie się języka tercjalnego: francuski po angielskim 


\section{Wprowadzenie}

Najnowsze opracowania na temat dydaktyki wielojęzyczności podkreślają znaczenie i rolę zintegrowanego nauczania językowego w procesie przyswajania kolejnych języków obcych (Candelier i in., 2007; Hufeisen i Neuner, 2004; Manno i Greminger Schibli, 2015; Moore, 2006; Widła, 2007; Zarate, Lévy i Kramsch, 2008). Wyniki badań wskazują na wyraźną synergię zasobów, wiedzy i umiejętności wyzwalającą się podczas procesu równoległego uczenia się różnych języków (Hufeisen i Neuner, 2004; Widła, 2011; Wokusch, 2008). Warto zatem w kształceniu językowym odnieść się do rozwiązań proponowanych w podejściach pluralistycznych i szukać powiązań pomiędzy poszczególnymi językami, które uczący się już znają, oraz tymi, które aktualnie przyswajają.

Odwołując się do proponowanej przez Candeliera klasyfikacji podejść pluralistycznych, którą po raz pierwszy zaproponował w ramach projektu FREPA/CARAP (Candelier i in., 2007: 7-8), zintegrowane nauczanie jest jednym z czterech podejść, obok otwarcia na języki, rozumienia (interkomprehensji) języków pokrewnych oraz podejścia międzykulturowego. Stosunkowo najwięcej opracowań można znaleźć na temat ostatniego z nich, gdyż od wielu lat cieszy się ono popularnością zarówno wśród teoretyków, jak i praktyków z dziedziny nauczania języków obcych. Liczne projekty i działania odnoszą się również do interkomprehensji (zob. np. GALAPRO, GALANET i in.). Z kolei otwarcie na języki cieszy się dużą popularnością ze względu na dostępność wielu interesujących materiałów dydaktycznych dla różnych grup wiekowych do wykorzystanie na zajęciach z języków obcych, np. wypracowanych w ramach projektów EVLANG i JaLing oraz innych ${ }^{1}$.

Zintegrowane nauczanie języków jest podejściem, na temat którego dopiero zaczynają się pojawiać konkretne opracowania, a wraz z nimi propozycje jego zastosowania. Dotyczy to szczególnie krajów, w których używa się jednocześnie dwóch i więcej języków obcych (np. w Szwajcarii oraz w Dolinie Aosty w północno-zachodnich Włoszech). Dodatkowym wyzwaniem dla zainteresowanych

\footnotetext{
${ }^{1}$ FREPA - A Framework for Pluralistic Approaches to Languages and Cultures/CARAP - Un Cadre de Référence pour les Approches Plurielles des Langues et des Cultures. Program ma na celu upowszechnienie narzędzi, jakie powstały w ramach projektu "System opisu pluralistycznych podejść do języków i kultur" (FREPA/CARAP) rozwijającego kompetencje uczniów na każdym poziomie edukacji w dziedzinie różnojęzyczności i wielokulturowości. Na oficjalnej stronie projektu FREPA w Centrum Języków Nowożytnych Graz można aktualnie znaleźć 75 propozycji scenariuszy zajęć prowadzonych zgodnie z założeniami podejścia otwarcia na języki: http://carap.ecml.at/CARAPTeachingmaterials/tabid/2355/language/fr-FR/Default.aspx [DW 5.01.2016].
} 
Angielski szansą dla francuskiego, czyli refleksja o zintegrowanym nauczaniu...

tym podejściem jest różnorodność używanych terminów powodująca niespójność terminologiczną. Stąd trudność w przyporządkowaniu każdemu z czterech podejść jednoznacznego odpowiednika w językach obcych².

\section{Stosowana terminologia}

W opracowaniach polsko-, francusko-, angielsko- i niemieckojęzycznych dotyczących zintegrowanego nauczania języków można znaleźć bardzo różne określenia, które zebrano w tabeli 1.

\begin{tabular}{|l|l|l|l|}
\hline \multicolumn{1}{|c|}{$\begin{array}{c}\text { Terminologia } \\
\text { polskojęzyczna }\end{array}$} & \multicolumn{1}{|c|}{$\begin{array}{c}\text { Terminologia } \\
\text { francuskojęzyczna }\end{array}$} & \multicolumn{1}{|c|}{$\begin{array}{c}\text { Terminologia } \\
\text { niemieckojęzyczna }\end{array}$} & $\begin{array}{c}\text { Terminologia } \\
\text { angielskojęzyczna }\end{array}$ \\
\hline $\begin{array}{l}\text { Zintegrowana dydaktyka } \\
\text { języków (obcych) }\end{array}$ & $\begin{array}{l}\text { Didactique intégrée des } \\
\text { langues (étrangères) }\end{array}$ & $\begin{array}{l}\text { Integrierte Sprachendidaktik in un- } \\
\text { terschiedlichen gelernten Sprachen }\end{array}$ & $\begin{array}{l}\text { Integrated didactic ap- } \\
\text { proache }\end{array}$ \\
\hline $\begin{array}{l}\text { Dydaktyka skoordyno- } \\
\text { wana językowo }\end{array}$ & $\begin{array}{l}\text { Didactique coordonnée } \\
\text { des langues }\end{array}$ & $\begin{array}{l}\text { Koordination des Sprachenunter- } \\
\text { richts }\end{array}$ & $\begin{array}{l}\text { Coordination of lan- } \\
\text { guage teaching }\end{array}$ \\
\hline $\begin{array}{l}\text { Dydaktyka międzyjęzy- } \\
\text { kowa }\end{array}$ & Pédagogie interlangues & $\begin{array}{l}\text { Theorien des Zweitspracherwerbs } \\
\text { Interlanguage }\end{array}$ & Interlanguage theory \\
\hline $\begin{array}{l}\text { Dydaktyka wielojęzyczno- } \\
\text { ści }\end{array}$ & $\begin{array}{l}\text { Didactique du plurilin- } \\
\text { guisme }\end{array}$ & Mehrsprachigkeitsdidaktik & Multilingual didactics \\
\hline $\begin{array}{l}\text { Zintegrowany program } \\
\text { nauczania }\end{array}$ & Curriculum intégré & Integrierte Curricula & $\begin{array}{l}\text { Tertiary language } \\
\text { learning }\end{array}$ \\
\hline $\begin{array}{l}\text { Nauczanie/uczenie się ję- } \\
\text { zyków tercjarnych }\end{array}$ & $\begin{array}{l}\text { Apprentissage d'une } \\
\text { langue tertiare }\end{array}$ & Tertiärsprachenlernen &
\end{tabular}

Tabela 1: Zintegrowane nauczanie języków - stosowana terminologia.

Wymienione powyżej terminy oznaczają w przybliżeniu to samo i zależą od stanowiska autora oraz trendów badawczych. Odnoszą się np. wyłącznie do języków obcych nauczanych w szkole (nauczanie języka trzeciego) lub biorą pod uwagę języki w kontekście migracji (dydaktyka skoordynowana językowo), język lokalny/wernakularny (dydaktyka międzyjęzykowa), czy też inne języki nauczane bądź używane poza środowiskiem szkolnym (zintegrowany program nauczania) (Brohy, 2008: 11; Manno i Greminger Schibli, 2015: 50). Próba jednoznacznego przyporządkowania terminologicznego znaczenia danemu pojęciu jest trudna, gdyż nadal toczy się dyskusja dotycząca ich ostatecznego kształtu i wymiaru.

\footnotetext{
${ }^{2} \mathrm{~W}$ oparciu o analizę terminologii stosowanej w wielu publikacjach na temat wielojęzyczności proponujemy przyjąć następujące ekwiwalenty: zintegrowane nauczanie (fr. didactique intégrée, ang. integrated didactic approaches), otwarcie na języki (fr. éveil aux langues, ang. language awakening lub language awareness), interkomprehensja (fr. intercompréhension entre les langues, ang. mutual intelligibility of languages) i podejście międzykulturowe (fr. approche interculturelle, ang. intercultural approach).
} 


\section{Zintegrowane nauczanie języków - próba definicji}

Zintegrowane nauczanie języków polega na skoordynowaniu procesu nauczania/uczenia się różnych języków obcych przez wyszukiwanie i znajdowanie powiązań między wszystkimi lub wybranymi językami nauczanymi w szkole i/lub poza nią. Może obejmować również język ojczysty. Podejście zintegrowane opiera się na podstawowej zasadzie uczenia się: wykorzystać to, co jest znane, w celu przybliżenia i odkrycia tego, co mniej znane lub nieznane. Zakłada więc, że każdy nowy język wspomaga lepsze zrozumienie języków poznanych uprzednio oraz to, że wcześniej poznane języki pomagają w zrozumieniu i użyciu kolejnych. Tym samym zintegrowane nauczanie języków promuje i zachęca do otwarcia procesu nauczania/uczenia się jednego języka na rzecz nauczania kolejnego.

Tworząc zintegrowany program nauczania języków, należy dokładnie określić miejsce i rolę każdego z nich w nawiązaniu do ogólnych celów językowo-kulturowych oraz w odniesieniu do określonych kompetencji dla każdego z osobna (mogą być od siebie różne) (Candelier i in., 2007; Moore, 2006; Roulet, 1995). Takie podejście jest stosowane np. we francuskojęzycznej części Szwajcarii i zostało opisane w dokumentach dotyczących polityki językowej (CIIP, 2003).

Poszukiwanie zbieżności między językami jako przedmiotami nauczania ma na celu podniesienie jakości i skuteczności procesu nauczania/uczenia się. Jako przykład dopracowanej formuły dydaktyki zintegrowanej można przyjąć niektóre formy nauczania dwujęzycznego czy też nauczanie języka trzeciego, język niemiecki po angielskim lub angielski po niemieckim (Candelier i Schröder-Sura, 2012: 5).

$\mathrm{Na}$ polskim gruncie edukacyjnym tego typu podejście oznaczałoby zmianę paradygmatu ze zwyczajowo stosowanego oddzielnego nauczania poszczególnych języków angielskiego, francuskiego, hiszpańskiego i niemieckiego na skoordynowane nauczanie dwóch lub więcej języków.

\section{Zmiana paradygmatu szansą dla pozostałych (obok angielskiego) języków}

Zmiana podejścia w nauczaniu stworzyłaby nową przestrzeń dla różnych języków obcych i tym samym wpłynęłaby korzystnie w polskiej rzeczywistości edukacyjnej na stosunek do uczenia się, obok języka angielskiego, również innych języków. Od wielu lat język angielski jest uważany za wiodący w edukacji ze względu na rolę lingua franca, którą odgrywa w odbiorze decydentów, rodziców i uczniów. Postrzeganie języka angielskiego jako jedynego klucza do sukcesów na rynku pracy wpływa negatywnie na chęć uczenia się i nauczania pozostałych języków obcych. Dlatego też statystyki dotyczące nauczania np. języka francuskiego 
znacznie się różnią od tych dotyczących języka angielskiego ${ }^{3}$. Zasadnym wydaje się zatem odejście od dotychczasowego sposobu nauczania kolejnych języków w odizolowaniu od angielskiego na rzecz wykorzystania synergii pomiędzy nimi (np. między angielskim i francuskim).

Zdecydowana większość polskich uczniów uczy się języka angielskiego już od pierwszych lat szkolnych (a czasami nawet wcześniejszych). Należałoby zacząć postrzegać tę sytuację jako okoliczność sprzyjającą wytworzeniu zasobu wiedzy i umiejętności oraz strategii uczenia się do wykorzystania w procesie nauczania języka francuskiego jako drugiego po angielskim (i trzeciego po języku ojczystym). Tym bardziej, że liczba godzin przeznaczonych na naukę drugiego języka obcego w polskim systemie edukacyjnym jest mniejsza niż na naukę pierwszego języka obcego, którym najczęściej jest język angielski. Poza tym obowiązkowe nauczanie pierwszego języka obcego rozpoczyna się według aktualnie obowiązującej podstawy programowej już w przedszkolu ${ }^{4}$, w wieku 5 lat, podczas gdy na drugi język przychodzi czas dopiero w gimnazjum. Cele stawiane w nauczaniu języka drugiego nie odbiegają od tych sprecyzowanych dla pierwszego. Jednakże krótki czas nauczania oraz niewielka liczba przeznaczonych godzin znacząco utrudniają ich osiągnięcie i tym samym powodują, że większość uczniów wybiera na egzaminie gimnazjalnym oraz na maturze język angielski zamiast jakiegokolwiek innego. Potwierdzają to m.in. badania dotyczące powszechności nauczania języków obcych w Polsce prowadzone przez Ośrodek Rozwoju Edukacji (Braunek, 2013) oraz Główny Urząd Statystyczny (2014).

W świetle przytoczonych powyżej informacji, aby uzyskać lepsze efekty w nauczaniu drugiego języka obcego, należy sięgać po takie rozwiązania dydaktyczne, które pozwolą na ergonomiczne pod względem kognitywnym wykorzystanie czasu nauki. Istniejąca w polskim systemie edukacyjnym chronologia - angielski przed francuskim - mogłaby zostać wykorzystana w celu przyspieszenia procesu uczenia się języka francuskiego. Istnieją już pierwsze badania

\footnotetext{
${ }^{3}$ Nauczanie języków obcych jako przedmiotu obowiązkowego w szkołach dla dzieci i młodzieży (łącznie ze specjalnymi) oraz policealnych w roku szkolnym 2014/2015: angielskiego $95 \%$ ogółu uczniów, niemieckiego 35,8\%, rosyjskiego 4,3\%, francuskiego 2,6\%, hiszpańskiego 1,6\%, włoskiego 0,4\%, innego 0,1\%. Niektórzy uczniowie uczą się więcej niż jednego języka obcego, dlatego suma odsetek przekracza 100\%. Za: Oświata i wychowanie w roku szkolnym 2014/2015, Główny Urząd Statystyczny, Warszawa 2015. [online: file:///C:/Users/GPS/Downloads/oswiata_i_wychowanie_w_roku_szkolnym_20 14-2015.pdf; DW 3.06.2016].

${ }^{4}$ Rozporządzenie Ministra Edukacji Narodowej z dnia 30 maja 2014 r. zmieniające rozporządzenie w sprawie podstawy programowej wychowania przedszkolnego oraz kształcenia ogólnego w poszczególnych typach szkół.
} 
przeprowadzone w Polsce ${ }^{5}$, które potwierdzają, że wykorzystanie zasobów językowych ucznia trójjęzycznego na poziomie edukacji ponadgimnazjalnej pozwala skrócić nawet o jedną trzecią czas opanowania umiejętności posługiwania się kolejnym językiem obcym (Widła, 2007). Do podobnych wniosków doszli badający efekty zintegrowanego nauczania języków w Szwajcarii. Po pięciu latach od wprowadzenia reformy w nauczaniu języków okazało się, że uczniowie szkół podstawowych, którzy przed rozpoczęciem nauki języka francuskiego uczyli się od dwóch lat języka angielskiego, osiągali lepsze rezultaty od kolegów, którzy nie uczyli się wcześniej angielskiego (Egli Cuenat, 2012: 2223). Warunkiem sine qua non sukcesu jest jednak świadome odnoszenie się przez nauczyciela do wcześniejszych doświadczeń językowych uczniów.

\section{Zastosowanie zintegrowanego nauczania językowego w nauczaniu drugiego języka obcego}

W literaturze przedmiotu pojawiały się różne hipotezy na temat zgubnych skutków transferu negatywnego (interferencji językowej). Aktualne tendencje w dydaktyce nauczania języków obcych kładą nacisk przede wszystkim na umiejętność rozpoznania interferencji w celu uniknięcia ryzyka, które ze sobą niesie (Manno i Greminger Schibli, 2015: 51-52). Ci sami naukowcy, powołując się na badania Kleina i Stahlhofen (tamże), podkreślają znaczenie transferu pozytywnego $\mathrm{w}$ formie internacjonalizmów. Otóż ich wpływ na przyswajanie języka obcego jest dla uczącego się pięć razy korzystniejszy niż zakładany skutek negatywny, który łatwo zminimalizować, a nawet wykluczyć poprzez kontekstualizację. Najnowsze badania przeprowadzone pod egidą Widły

\footnotetext{
${ }^{5}$ Projekt badawczy przeprowadzony przez Instytut Języków Romańskich i Translatoryki Uniwersytetu Śląskiego w latach 2006-2009 miał na celu opracowanie metodologii badań nad przyswajaniem języka francuskiego jako trzeciego po języku ojczystym i angielskim. Wymiernym efektem tych badań, poza przedstawieniem teorii na temat rozmaitych aspektów badanego zjawiska, jest suplement do podręczników nauki języka francuskiego w wersji elektronicznej (Ćwiczenia z języka francuskiego, Katowice 2009), składający się z odpowiednio dobranych ćwiczeń interaktywnych, umożliwiających szybkie wyeliminowanie transferu negatywnego. Widła we wstępie do ww. suplementu zatytułowanym „Jak to działa” stwierdza: „Uczeń trójjęzyczny różni się mocno od dwujęzycznego. Okazuje się, że najciekawsze różnice ukazują się w momencie pewnej stabilizacji, po około 300 godzinach przyswajania materiału, kiedy nabywa się sprawności pozwalające na w miarę skuteczne komunikowanie się w języku obcym. Tak szybkie postępy możliwe są oczywiście dzięki znajomości drugiego języka - przez pewną bliskość, zwłaszcza słownictwa, bo wszelkie luki wiedzy kompensowane są w o wiele większym stopniu kreatywnością uczniów".
} 
(2011: 54-55) pozwoliły na dookreślenie pojęcia świadomego i nieświadomego transferu pozytywnego: „Transfer pozytywny, czyli produkcja poprawnych form w L2, gdzie poprawność oznacza zbieżność z użyciem, występuje częściej nieświadomie, na zasadzie prostej kalki językowej. Świadomy transfer występuje, kiedy uczący się zgadują przy produkcji tekstu lub mowy w L2, ponieważ nie opanowali lub zapomnieli użycia danego elementu w L2. Tacy użytkownicy języka mogą być świadomi różnic, ale brakuje im umiejętności w L2 i w konsekwencji podpierają się swoim językiem ojczystym. W przypadku osób posługujących się kilkoma językami obcymi, transfer czasami zachodzi między L2 i L3, a czasami między L1 i L36 ${ }^{6}$. Na przykład Polak mówiący po angielsku i niemiecku może założyć, że reguły języka angielskiego odnoszą się również do niemieckiego" (Widła, 2011: 54-55).

Podobnie jest z wiedzą proceduralną i deklaratywną w procesie przyswajania języka obcego. Przyjmuje się mianowicie, że w przypadku przyswajania L3 uczący się korzystają z wiedzy proceduralnej nabytej w L1 i/lub w L2. Uczenie się kolejnego języka opiera się zatem na dotychczasowym doświadczeniu w tym zakresie, a więc na wypracowanym uprzednio katalogu kognitywnej analizy językowej, którą dostosowuje się do struktur kolejnego języka (Manno i Greminger Schibli, 2015: 53). Badacze podkreślają wykorzystanie m.in. nabytych uprzednio strategii uczenia się, rozumienia oraz produkcji.

„Wiedza deklaratywna w L2 (system języka) nie musi być na nowo konstruowana ze względu na wiele podobieństw i pokrewieństwo językowe między angielskim i francuskim" (Hufeisen i Neuner, 2004: 174), np. w zakresie słownictwa. Ponieważ celem niniejszego artykułu nie jest wskazanie konkretnych przykładów ćwiczeń, zadań czy też działań integrujących języki na określonym etapie edukacyjnym i poziomie nauczania, ograniczymy się do ogólnego przybliżenia zamysłu łączenia zasobów.

Jednym z obszarów do wykorzystania jest słownictwo. Przyjmuje się ${ }^{7}$, że jedna trzecia słownictwa angielskiego pochodzi z języka francuskiego. Wliczając w to słowa pochodzenia łacińskiego i inne wpływy romańskie, leksemy, które nie są pochodzenia germańskiego, stanowią więcej niż połowę słownictwa języka angielskiego. Można spotkać się z opinią, że język angielski jest najbardziej łacińskim ze wszystkich języków germańskich. W ostatnich latach wiele anglicyzmów

\footnotetext{
${ }^{6} \mathrm{Na}$ polskim gruncie edukacyjnym przyjmuje się, że L1 to język ojczysty, L2 - pierwszy język obcy i L3 - drugi język obcy.

${ }^{7}$ Najnowsze dane na ten temat zebrał Donisthorpe z British Council w artykule pt. „Ile angielskiego w angielskim? Język globalny”. Artykuł ukazał się w wydaniu on-line czasopisma „Polityka” z dn. 28.11.2014 [online: http://www.polityka.pl/tygodnikpolityka/ludzieistyle/1600757,1,ile-angielskiego-w-angielskim.read; DW 3.06.2016].
} 
przeniknęło z kolei do języka francuskiego, co dodatkowo wpłynęło na zwiększenie liczby wspólnych słów. Praca ze słownictwem może więc być dobrym początkiem w tworzeniu zintegrowanego podejścia na zajęciach z języka obcego. Innym pomysłem do wykorzystania jest znalezienie powiązań na poziomie fonologicznym, np. przeciwieństwa fonologiczne i fonemy wspólne dla obu języków. W obszarze składni i morfologii można m.in. przyjrzeć się szykowi zdań w języku angielskim i porównać go z francuskim albo porównać reguły stopniowania.

Gotowe pomysły na wykorzystanie i tworzenie połączeń między językami można znaleźć w najnowszych podręcznikach i materiałach dydaktycznych, które ukazały się na niemieckim i szwajcarskim rynku edukacyjnym ${ }^{8}$. Zostały skonstruowane wokół czterech aspektów (Egli Cuenat, 2012: 24-25):

- wspólnego słownictwa (dobór tekstów, w których występuje ok. 30\% wspólnego dla obu języków słownictwa, refleksja nad rodzajami podobieństw graficznych i fonicznych, nad „fałszywymi przyjaciółmi” interferencjami oraz transferami pozytywnymi, zadania ułatwiające dokonywanie transferu);

- wspólnych strategii uczenia się (kognitywnych, np. clustering, afektywnych czy metakognitywnych);

- strategii czytania, słuchania, pisania i mówienia;

- otwarcia na języki.

Oprócz nowych materiałów ważną pomoc stanowią dotychczasowe wydania Europejskiego Portfolio Językowego (EPJ) wspierające rozwój uczenia się transwersalnego, samoocenę oraz refleksję nad własną biografią językową.

Ostatnie wymienione narzędzie, do którego mamy łatwy dostęp w Polsce ${ }^{9}$, może być wykorzystane do tworzenia projektów edukacyjnych (w przeszłości znanych bardziej pod nazwą ścieżek międzyprzedmiotowych), których tematyka odnosiłaby się do integrowania zasobów zdobytych w procesie przyswajania języków obcych. Można po raz kolejny skorzystać z doświadczeń szwajcarskich nauczycieli, którzy w ramach wspólnego międzykantonalnego projektu „Passepartout" ${ }^{10}$ stworzyli

\footnotetext{
${ }^{8}$ Brücken zwischen Young World und envol i Brücken zwischen Explorers und envol dla uczniów w wieku 11-14 lat, dla których pierwszym językiem obcym jest angielski, a drugim - francuski. Podręczniki dla młodszych i starszych dzieci stosowane równolegle dla języka francuskiego: Mille feuilles oraz angielskiego New World. Podręcznik dla młodzieży: Découvrons le français : Französisch interlingual.

${ }^{9}$ Europejskie Portfolia Językowe dla wszystkich grup wiekowych są dostępne on-line na stronie Ośrodka Rozwoju Edukacji: http://www.ore.edu.pl/jezyki-obce/4343-europejskie-portfolio-jezykowe-epj [DW 7.01.2016].

${ }^{10}$ 25.03.2004 r. CDIP (Szwajcarska Konferencja Kantonalnych Ministrów Edukacji) zdefiniowała swoją strategię i program prac w dziedzinie nauczania języków obcych w
} 
skoordynowane programy nauczania dwóch języków wokół następujących obszarów: kompetencji językowej w ujęciu zadaniowym, znajomości języków i kultur oraz umiejętności strategicznych. Projekty edukacyjne w polskiej szkole sformułowane wokół pierwszego obszaru mogłyby być oparte o podstawę programową języka obcego nowożytnego dla właściwego etapu edukacyjnego, wytyczne zawarte w Europejskim Systemie Opisu Kształcenia Językowego (2003) oraz polskie wersje EPJ. W przypadku drugiego (otwarcia na języki i edukacji interkulturowej) i trzeciego obszaru (umiejętności uczenia się, jak się uczyć) można, oprócz EPJ, zastosować rozwiązania zaproponowane w programie FREPA/CARAP.

Z doświadczeń szwajcarskich wynika, że koordynacja międzyjęzykowa może być oparta na dwóch wzorcach: pierwszy (najtrudniejszy do realizacji na polskim rynku edukacyjnym) to opracowanie podręczników i/lub materiałów zawierających gotowy zestaw tekstów i zadań ułatwiających znalezienie połączeń między językami, drugi to autorskie projekty edukacyjne oparte na założeniach dydaktyki zintegrowanego nauczania języków.

Stosując pluralistyczne podejście w procesie nauczania języków obcych należałoby więc zwiększyć udział transferu pozytywnego oraz zapobiegać transferowi negatywnemu. Wzmocnienie transferu pozytywnego jest możliwe np. poprzez wczesne tworzenie świadomości językowej (w tym różnojęzycznej i międzyjęzykowej) oraz usystematyzowanie wspólnych, podobnych odniesień i połączeń.

\section{Wnioski}

Biorąc pod uwagę uczących się jako podmioty społeczne jest ważne, aby bacznie obserwować rzeczywistość, w której funkcjonują i którą przyjdzie im współtworzyć. Dzisiejszy świat, a tym bardziej świat jutra, jest i będzie wielokulturowy. Proces internacjonalizacji nie przekłada się bowiem na standaryzację oraz uniwersalność punktów widzenia i odniesienia, ale raczej na wprowadzenie w różnorodność, niepewność i niestabilność. W tej sytuacji niezwykle istotne staje się

ramach kształcenia obowiązkowego. Jego głównym celem jest nauczanie dwóch języków obcych od trzeciego i piątego roku kształcenia obowiązkowego. Efektem końcowym projektu „Passepartout" jest stworzenie wielojęzycznego repertuaru uczniów na bazie poszczególnych języków: L1, języków obcych i innych języków, z którymi uczeń ma do czynienia. Języki nie są rozpatrywane indywidualnie, ale jako elementy przyczyniające się do rozwoju repertuaru językowego jako całości przekraczającej jego składowe. Pogląd ten ma konsekwencje w zakresie dydaktyki wielojęzyczności (w terminologii „Passepartout”), gdyż oznacza zbliżenie i wzajemne korzyści płynące z nauczania językowego, które jest nazywane dydaktyką zintegrowaną lub skoordynowaną. 
zrozumienie inności, a szkoła, która coraz częściej staje się miejscem przyjmującym uczniów/studentów różnych kultur i języków, powinna odgrywać wyznaczoną i specjalną rolę $\mathrm{w}$ tym procesie. W szerokim rozumieniu dydaktyka zintegrowana obejmująca różne języki, które tworzą pomosty w przyswajaniu kolejnych, może wobec tego odegrać niebagatelną rolę wychowawczą.

\section{BIBLIOGRAFIA}

Brohy, C. 2008. „Didactique intégrée des langues: évolution et définitions”. Babylonia, 1: 9-11. Candelier, M., Camillieri-Grima A., Castellotti, V., De Pietro, J.-F., Lörincz, I., Meißner, F.-J., Noguerol, A., Schröder-Sura, A. i M. Molinié. 2007. FREPA. Framework of reference for pluralistic approaches to languages and cultures. Strasbourg: Council of Europe, Graz: ECML.

Candelier, M. i A. Schröder-Sura. 2012. „Wspieranie rozwoju kompetencji różnojęzycznych i międzykulturowych w klasie szkolnej”. Języki Obce w Szkole, 4: 4-11.

Egli Cuenat, M. 2012. „Création de matériaux d'enseignement pour un apprentissage coordonné des langues?”. Babylonia, 1: 22-28.

Hufeisen, B. i G. Neuner. 2004. Le concept de plurilinguisme: Apprentissage d'une langue tertiaire-l'allemand après l'anglais. Strasburg: CELV, Conseil de l'Europe.

Manno, G. i C. Greminger Schibli. 2015: „Les synergies offertes par la didactique intégrée des langues - profitons-en dans l'enseignement du français deuxième langue étrangère!". (w) Weiterbildung und Mehrsprachigkeit - Formation continue et plurilinguisme - Further education and plurilingualism. (red. M. Weil i M. Vanotti). Bern: Hep-Verlag, str. 46-63.

Moore, D. 2006. Plurilinguismes et école. Paryż: LAL Didier.

Roulet, E.1995. „Peut-on intégrer l'enseignement-apprentissage décalé de plusieurs langues ?". Babylonia, 2: 22-25.

Widła, H. 2007. L'acquisition du français - langue troisième. Problèmes méthodologiques et implications pratiques. Katowice: Wydawnictwo Uniwersytetu Śląskiego.

Widła, H. 2009. Ćwiczenia z języka francuskiego (na płycie CD). Katowice: Wydawnictwo Uniwersytetu Śląskiego.

Widła, H. 2011. „Skuteczność nauczania drugiego języka obcego - próba zastosowania wyników badań w praktyce". Lingwistyka stosowana, 4: 53-67.

Wokusch, S. 2008. „Didactique intégrée des langues (étrangères) à l'école: vers l'enseignement des langues de demain". Prismes Revue Pédagogique HEP, 8: 30-34.

Zarate, G., Lévy, D. i C. Kramsch. 2008. Précis du plurilinguisme et du pluriculturalisme. Paryż: Editions des archives contemporaines. 


\section{Netografia}

Braunek, A. 2013. Powszechność nauczania języków obcych w roku szkolnym 20112012. Raport Ośrodka Rozwoju Edukacji. file:///C:/Users/GPS/Downloads/powszechnosc_nauczania_jezykow_2011_2012.pdf [DW 5.01.2016].

CIIP (Conférence intercantonale de l'instruction publique de la Suisse romande et du Tessin). 2003. Déclaration de la CIIP relative à la politique de l'enseignement des langues en Suisse romande du 30 janvier 2003. http://www.axl.cefan.ulaval.ca/europe/suisse-CIIPSRT-2003.htm [DW 05.01.2016].

GUS (Główny Urząd Statystyczny). 2014. Oświata i wychowanie w roku szkolnym 2013-2014. file:///C:/Users/GPS/Downloads/oswiata_i_wychowanie\%20(1).pdf (DW 05.01.2016). 